\title{
AC 2010-1543: SIMULATING THE COLLABORATIVE DESIGN PROCESS THROUGH A MULTIDISCIPLINARY CAPSTONE PROJECT
}

\section{Charlie Setterfield, Sinclair Community College}

Charlie Setterfield is an Assistant Professor of Architectural Technology. B.A. Wittenberg University, M.Arch Ohio State University. With more than 18 years experience in the architectural and construction industries, including responsibilities in all aspects of architectural project delivery and construction management, Mr. Setterfield brings real-world experience to the classroom. Setterfield's courses focus on materials and means of construction, construction document preparation, "green building", professional practice and building codes. As a sole proprietor, Setterfield provided residential design services, specializing in timber framing and environmental responsibility. As a Plans Examiner, Setterfield balanced building code requirements with real-life owner and contractor concerns.

\section{Eric Dunn, Sinclair Community College}

Eric Dunn is an associate professor in the Civil Engineering and Architectural Technologies department at Sinclair Community College. He has a masters degree in project management from Wright State University in Dayton, Ohio. He specializes in teaching construction management, cost estimating, means of construction and various CAD software packages. Dunn's professional experiences include on site construction management, facilities management and as an estimator for a design/build firm. He is an affiliate professor for Project Lead the Way which introduces high school students to various disciplines of engineering.

\section{Russell Marcks, Sinclair Community College}

Russ Marcks is a Professor in the Heating Ventilation and Air Conditioning Department at Sinclair Community College in Dayton, $\mathrm{OH}$. 


\section{Simulating the Collaborative Design Process Through a Multidisciplinary Capstone Project}

\section{Abstract}

This paper highlights the results of a newly redesigned capstone course, incorporating objectives and priorities as defined by the department's various discipline-specific advisory boards. Six technology disciplines (Architecture, Civil Engineering, Construction Management, HVACR, Environmental and Mechanical) worked together to research, design and document a highly energy efficient building. Three student teams were formed, providing very different solutions to the design challenge. The focal point of this paper is to summarize the simulation of workforce dynamics and how to work more closely with advisory board members.

An important aspect of the assignment was Integrated Project Delivery (IPD), requiring students of diverse disciplines to work together to formulate a feasible solution. Professors worked with students to foster a sense of community that allowed cross-disciplinary collaboration, including hosting a visiting lecturer who specializes in IPD who worked with both faculty and students prior to the start of the project. Technology allowing for group communication was employed by the teams and monitored by faculty throughout the course.

Building Information Modeling (BIM) was a cornerstone of the challenge, driving students to explore new technologies of modeling and construction. Autodesk's Revit, a component-driven building modeling program, was the design software of choice. Revit models were coupled with energy analysis, estimating, rendering, and other design programs. A designated server on campus was established to allow for work sharing and information management.

While students used technology specific to their disciplines, information and decisions were compiled to allow access by the team and client. The project guidelines mandated the inclusion of green technologies, including renewable energy. Net Zero Energy, which requires designers to balance a building's energy consumption with its ability to generate power, required team's diligence in their IPD effort.

Layering on top of the various discipline-specific and IPD priorities was a goal to explore the pedagogy of technology. Students matriculating in the current technological environment face significant impact on their productivity, communication and research activities as a result of technology, some positive and some negative. As a result, a goal was to explore the use of technology and pedagogical theory to help guide the capstone effort. 


\section{Paper Outline}

1. Introduction
a. Pedagogical Goals
b. Literature Review
c. College Demographics
d. Student Demographics
e. Previous Capstones
f. Advisory Panels and Professional Workplace Demographics
g. Integrated Project Design

2. The Current Capstone
a. Program
b. Net Zero Energy
c. Teams
d. Schedule
e. Pedagogical Approach
f. Industry Research
g. Results

3. Discussion
a. Challenges to Student Success
b. Strengths of Student Teams
c. Targets for Improvement
d. Successes of Capstone Course 2009

4. Conclusions
a. Challenges
b. Strengths of Student Teams
c. Suggested Improvements
d. Successes

5. References 


\section{Introduction}

\section{A. Pedagogical Goals}

The goal of the capstone studio was three-fold:

1. Challenge students to design a solution incorporating their discipline-specific contributions on a diverse team while utilizing Integrated Project Design concepts.

2. Allow students to explore net zero energy design options for a large commercial building.

3. Encourage students to embrace technology to facilitate the learning process.

We developed an approach to the studio which allowed students to develop their own team leadership and management styles.

\section{B. $\quad$ Literature Review}

There is a variety of literature available to discuss the advent of blog and other web-based technologies in higher education, but it is usually indicated that "in those instances where educational applications of the blog are considered, this literature tends to be concentrated in the areas of teacher training and other professions where the use of reflective journals as a learning tool is accepted custom and practice..." ${ }^{[8]}$

Boulos, Maramba and Wheeler explore the potential of technology as an aid to pedagogy. In their paper they assert "Although the potential of wiki, blog and podcast technologies on higher education in the UK and elsewhere is immense, it is perhaps the combined use of the three applications as 'mind tools' that may yield the most powerful learning experiences. According to Jonassen et al. 'mindtools' act as cognitive reflection and amplification tools, aiding the construction of meaning, through the act of self-design of databases. Wikis in particular, and blogs to a lesser extent, enable such activities, and actively involve learners in their own construction of knowledge." [1]

Garrison and Akyol delve into the possibility of developing pedagogical practices to reinforce the creative collaborative process using technology. "Contrary to Salinas, there is one integrative model that has shown considerable potential to guide the adoption of instructional technologies in higher education - the Community of Inquiry framework. The purpose of this framework is to guide the use of instructional technologies in creating and sustaining deep and meaningful learning through reflection and discourse in online and blended learning environments." ${ }^{[3]}$

Koehler et. al conducted a study in which they followed the movement of "considering technology, pedagogy and content as being independent constructs towards a richer conception that emphasized connections among the three knowledge bases." ${ }^{[6]}$ It is critical for a set of disciplines which rely so heavily upon technology to embrace this transition, which we have attempted in this capstone course. 


\section{C. $\quad$ College Demographics}

Sinclair Community College offers 175 associate degrees and certificate programs, utilizing both traditional classroom and distance learning technologies. The college is accredited by NCACS, and is one of twelve Vanguard Learning colleges in the nation. Founded in 1878, Sinclair Community College serves three counties in southwest Ohio at five campus locations, and is an especially significant force in downtown Dayton, Ohio, employing 2,300 people and serving over 50,000 students per year. Enrollment in the fall of 2009 was over 25,000 unique students.

Sinclair Community College is committed to the continued vibrancy of its downtown main campus, which encompasses $62+$ acres and includes 20 buildings.

A recent reorganization of the instructional side of the college has resulted in the formation of five instructional divisions including:

- Business \& Public Services Division

- Distance Learning \& Instructional Support

- Liberal Arts, Communication \& Social Sciences

- Life \& Health Sciences

- Science, Mathematics \& Engineering (SME) Division

\section{Student Demographics and Profile}

The college serves students who fall into three general profiles:

- Traditional college students who are recent high school graduates. They are typically employed and may receive financial aid packages. They have chosen a community college for a variety of reasons, from financial to academic to lifestyle.

- Older college students who have spent years in the work force and have decided to start or finish a degree in hopes of entering a profession of choice, or improving their employment options within a given profession. These students typically are employed and many have family obligations. Employment and family may take priority over school work at times.

- Displaced workers who have been offered a retraining program through a government service or former employer. While these folks may not be obligated to a current job, they are usually anxious to complete a training program and move on to a new part of their lives. Typically these students are pursuing academic options very different from their former employment.

Additionally, the charter of the community college includes a stipulation that it is not a residential campus setting. The college does not include dormitories, apartments or any housing option. 


\section{E. $\quad$ Previous Capstones}

Capstone is the culmination of a course of study, incorporating the knowledge students have gained throughout their time at the college. During a typical capstone course a project is assigned requiring a team of students to work together to successfully complete over the period of one quarter (11 weeks).

Capstone courses have been used extensively in several of the Engineering Technology Design (ETD) areas of study. The ETD department includes six different degree programs including Architectural, Mechanical, HVAC, Civil, Construction Management (Civil) and Environmental Technologies. Typically, one or two disciplines are included in the capstone course. Characteristics of previous capstones may have included:

- Projects involving only one or two disciplines.

- Single-user software, such as AutoCAD, Solidworks, and Microsoft Office products.

- Non-digital formats, meaning that presentations were primarily prints taped to display boards. Digital presentations may or may not have been part of the capstone output requirement.

- Small scale projects

- Minimal collaboration, with student teams acting very independently.

For example, in the 2008 academic year, MET students designed a conversion kit to convert a 2cycle inboard sailboat engine to electric power complete with wind, solar, and tow generator battery recharge systems. While this was going on, the Architectural and Civil students collaborated on a small-scale building design. However, the HVAC students, with second group of Architectural students, conducted an energy audit for a local business concern. Of course, the Environmental students operated on their own dealing with local environmental concerns. Although each project was a valid capstone in its own right, multi-disciplinary collaboration was very minimal or completely lacking.

\section{F. Advisory Panel}

The college uses advisory panels to guide the development of curriculum. The advisory panels are comprised of industry leaders and professionals including, but not limited to, architects, engineers, contractors, managers, manufacturers, and sales representatives.

Their primary duties and responsibilities guiding curriculum and course development to ensure programs continue to meet the needs of the local community. Many advisors also serve as adjunct faculty, guest lecturers, and often provide co-op and internship opportunities for our students.

\section{Professional Marketplace Demographics}

Small to medium sized architectural, engineering and construction firms, with 5 - 40 employees. These firms typically work on regional projects, including healthcare, professional offices, senior living, government and educational projects. These firms complete predominantly AutoCAD based project work, but are moving toward Building Information Modeling (BIM) using Revit. 
Professional societies, such as the American Institute of Architects (AIA), American Society for Heating, Refrigeration and Air Conditioning Engineers (ASHRAE), etc. are included in the region.

Based on recommendations from these industry professionals, a more cross-disciplinary capstone approach was developed:

- Multiple discipline capstone

- Heightened collaboration

- Increased use of technology

- More complete building code compliance

As a result, a new capstone curriculum was developed to more closely simulate the industry trend toward integrated project delivery. Spring 2009 was the first implementation of this new strategy.

\section{G. $\quad$ Integrated Project Design/Delivery}

In an effort to prepare both students and faculty for the challenge of moving to a more completely Integrated Project Design/Delivery (IPD) model of capstone course, funding was secured by the department chair to bring in an expert lecturer in IPD. While serving as a professor of architecture, this instructor has developed a broad background in implementing the principles of IPD. Included among the activities the visiting lecturer participated in while at the college were:

- Delivering lecture to students and faculty regarding IPD process.

- Meeting with students to collaborate on IPD strategy and implementation.

- Lecture and discussion at professional society meeting (ASHRAE) to help local practitioners embrace IPD.

- Luncheon and discussion with advisory board members regarding IPD.

The idea of using an IPD approach in a capstone course format is not new, and some of our approach was guided by the findings of Suining, including "the presence of diverse team members within the same group permitted the students to experience a totally new teaching style that is different from the faculty." [2] It is hoped that this diversity manifests in students of differing disciplines imparting a portion of their knowledge on other team members early in the design process to help achieve the best solution possible for the client.

Integrated Project Design/Delivery (IPD) is being embraced by many of the professional societies included in the built environment disciplines. For instance, some recent entries on the American Institute of Architects and American Society for Heating, Refrigeration \& Air Conditioning Engineers included: 
Integrated Practice/Integrated Project Delivery (IP/IPD) leverages early contributions of knowledge and expertise through the utilization of new technologies, allowing all team members to better realize their highest potentials while expanding the value they provide throughout the project life cycle.

Through an integrated project delivery method, owners, designers, and builders can move toward unified models and improved design, construction, and operations processes.

\section{American Institute of Architects} website

Building information modeling is a very useful tool for collaboration and visualization, and can be a catalyst for change, but true collaboration and success only comes when the design process supports it. Integrated project delivery, supported by BIM, leverages the best of both tools and processes to empower team members. The advantages of BIM tools and the value of the IPD Process, while aligning the two in order to produce an efficient workflow, are discussed. Review of workflows, inhibitors, contracts and strategies for successful projects as well as successful examples are presented.

ASHRAE website

\section{Current Capstone}

\section{A. Program}

Students were charged to work together on teams to develop a solution to design a new engineering building for the college. The basic program included:

Academic Spaces Criteria:

Lecture Hall

Classrooms (10)

Computer Labs (12)

Construction Lab

Department Offices

Closets/Storage As needed

Restrooms As needed

\section{Community Spaces Criteria:}

Commons

Student Organization Offices

Common Workroom

Computer Workstations (public)
Garage

Fuel Station

Outdoor Spaces As needed

Documentation requirements:

Construction schedule

Cost estimate

Construction documents

Site survey

Building model (virtual)

Environmental impact statement

Energy usage analysis

Mechanical system design 


\section{B. Net Zero Energy consumption}

While net zero energy consumption has several varying definitions, for the purpose of the capstone, net zero energy meant that over the course of a year, the energy produced through renewable sources offset the consumption of energy used by the building. A net zero building would still be tied to the electrical grid and be tapped into natural gas supplies to provide power when the building is unable to generate what it consumes. A building might use more energy in the winter to provide heat than it is capable of producing but might generate excess power in spring were heating and cooling costs are low, but wind and sunlight are plentiful. Excess generated power would be sold back to the utility company.

Students addressed energy production through careful research based on cost, size, production levels, geographic location of the project, adjacent buildings, local codes, aesthetics, building usage data and proven methods. While each group incorporated wind turbines and solar tracking photovoltaic cells as part of their solution, each were unique in their overall design.

In order to achieve a zero sum over the course of the year students were encouraged to not only address ways to produce energy but also to save energy. This would include ways to reduce overall energy consumption through innovate designs that allow air to circulate the building naturally, using low wattage devices, using advanced heating and cooling methods such as geothermal, window placement to provide both light and heat, and advanced electronic controls that monitor occupancy and adjust lighting and temperature accordingly.

\section{Teams}

Three teams were established of approximately 20 students each. Due to the varying number of students in the six academic programs, not all teams had students from each discipline. For instance, Environmental Technologies had a limited number of students graduating. As a result, the environmental impact statement developed by these students was shared with other teams. This approach was chosen to avoid wide gaps is total project work.

Three computer equipped rooms were provided, one per each team. Computer stations were available for all students, as well as a central "presentation" podium. All stations provide internet access, as well as a wide variety of discipline-specific software:

- Autodesk® Civil 3D®

- Autodesk® Revit Architecture®

- Autodesk® Revit MEP®

- Autodesk ${ }^{\circledR}$ Revit Structure®

- ComCheck ${ }^{\mathrm{TM}}$

- Energy $10^{\mathrm{TM}}$

- Microsoft@ Office®

- Google® SketchUp®

- $\quad$ Timberline ${ }^{\circ}$ Estimating®

Students were allowed to determine their own management structure, establish work and meeting times outside of regular class meetings, etc. They were encouraged to use the technologies available to help manage this portion of the project. For instance, blogs were encouraged as a method of documenting meetings notes. Instructors would review the blogs on a regular basis 
and make comments as required. However, the vast majority of the information developed and shared on the blogs was student-generated.

\section{Schedule}

This first attempt at this IPD capstone course was Spring quarter, 2009. The standard quarter comprises eleven weeks, which must include meeting time for kickoff, reviews and final presentations.

Class met twice each week in the computer labs for three and a half hours each meeting.

\section{E. Pedagogical Approach}

Pedagogical goals were established to help faculty guide student work during the capstone. These included allowing student teams to develop their own approach to team management and inclusion. Suining confirmed Guerin's assertion that "design of human environments requires an awareness of related disciplines, and understanding of interdisciplinary processes, and competency in teamwork." ${ }^{[2]}$ The IPD approach to practice, as well as studio, follows this pedagogical approach.

Further, we relied on student leadership to naturally evolve and develop over the course of the capstone work. While this did occur, it was obvious that some students were much less comfortable with a "hands-off" approach by faculty when it came to "refereeing" their efforts. However, this hands-off approach is part of our pedagogical plan, and confirmed by Nutall et al. at Cal Poly, San Luis Obispo: "The architectural engineering program...relies on student, not faculty, leadership. This student led approach provides new opportunities for student development and learning beyond the traditional capstone project models reported in prior literature." [7]

Additionally, faculty designed a course which would allow for a blended learning environment, allowing students to work in various locations and at all times. However, the challenge of this model falls upon the student team leadership to manage the actual productivity and contribution of all team members. Per Georgina and Hosford, "Space and time constraints are less restrictive and offer more opportunities for collaboration of learners." ${ }^{[4]}$ So the goal of our course was to allow disparate discipline students to achieve this higher degree of collaboration through the technology tools we provided them. "The potential of using the internet as a teaching resource and tool, combined with using the most valued characteristics of face to face learning experiences reinforce blended learning advantages." [4]

Faculty are concerned with the genuine embracing of technology by students as well as faculty. Georgina and Olson suggest that this is a critical factor in the success of technologically enhanced pedagogy. They cite several studies which posit that the rush to embrace online and distance learning has been driven by a desire for profit and economic efficiency. ${ }^{[5]}$ Their second scenario of a technologically enhanced traditional classroom and pedagogy is the direction we chose for our revised capstone effort. 


\section{F. Industry Research}

Students made contact with some industry professionals to conduct research and schedule guest speakers. These speakers would be made available to all three teams, but would be hosted in the lab of the initiating team. Topics included solar energy technology, heat recovery technology, roofing, etc. Without exception, industry professionals were very willing to assist students with design and technical aspects of their projects. It was good to see this initiative being demonstrated by some students.

However, most teams failed to follow up and secure the assistance offered by the industry professionals. It seems that students are not aware of the value of the offered assistance to their project. Additionally, it may not be clear to students that they need to make industry connections to help with employment and continued success in their respective businesses.

\section{G. Results}

The three teams developed three distinct solutions to the challenge. Each has strengths and weaknesses. The images presented here have not been altered from the originals submitted by the teams, with the exception of sizing them to fit this document.

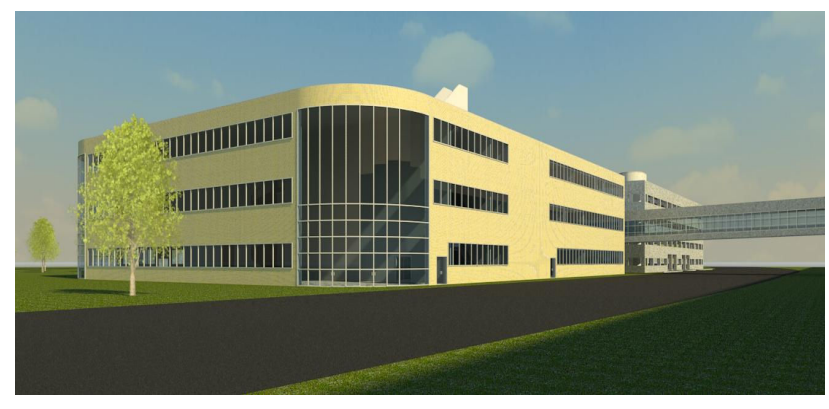

Capstone Studio 2009. Team One, exterior rendering

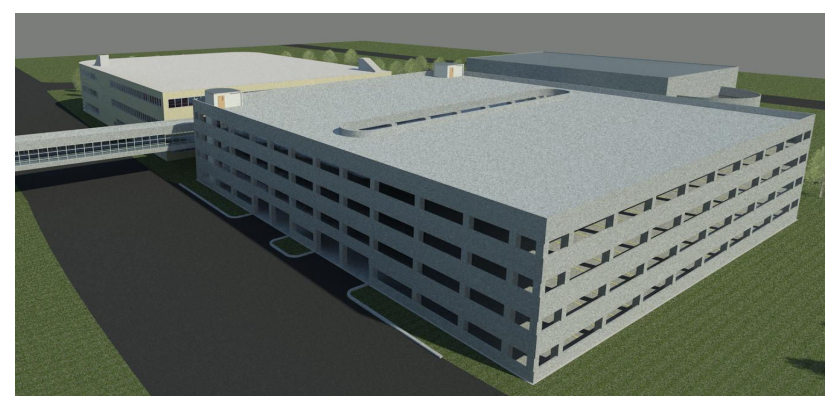

Capstone Studio 2009. Team One, exterior rendering

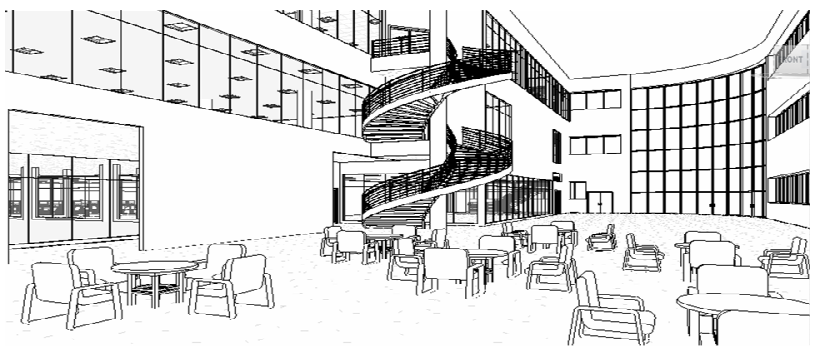

Capstone Studio 2009. Team One, interior view

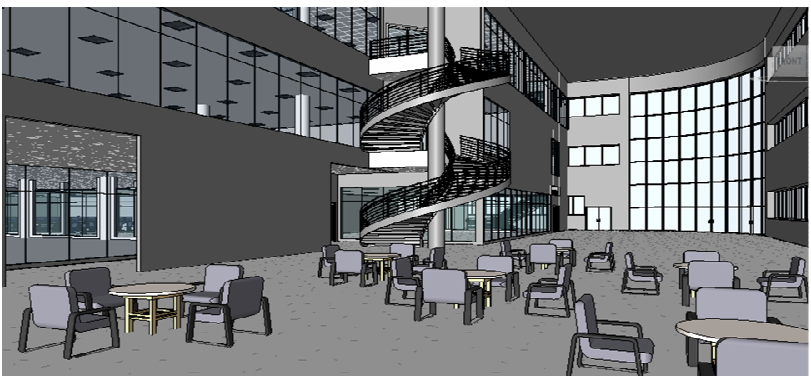

Capstone Studio 2009. Team One, interior view with shading 


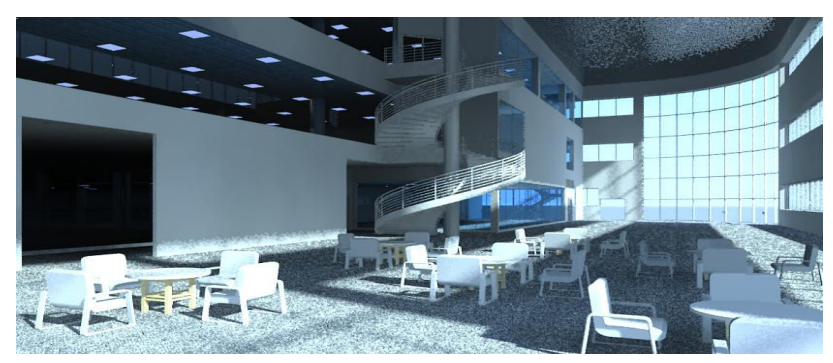

Capstone Studio 2009. Team One, interior rendering

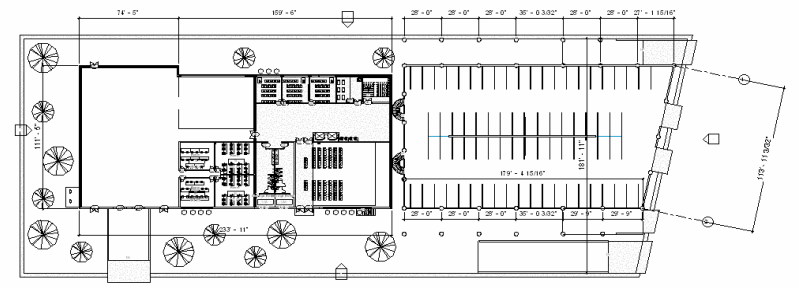

Capstone Studio 2009. Team Two, typical floor plan

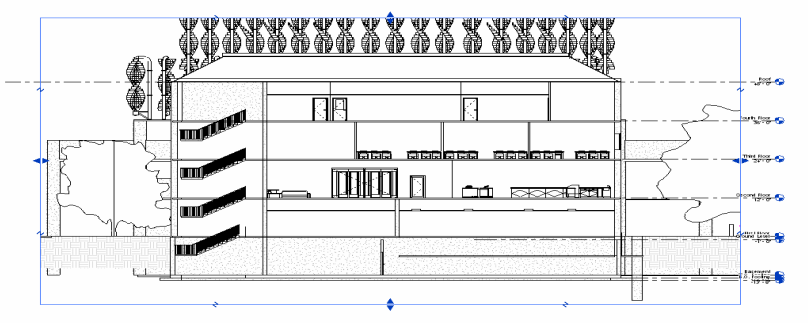

Capstone Studio 2009. Team Two, section

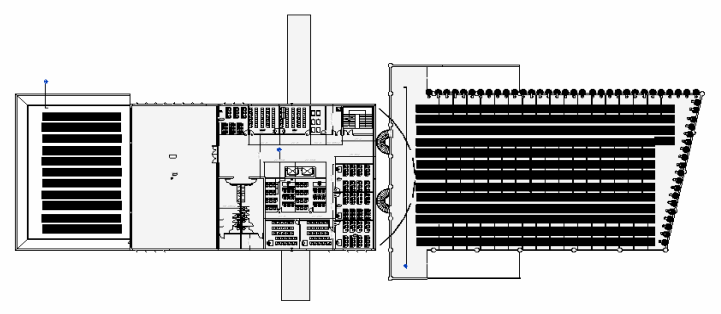

Capstone Studio 2009. Team Two, roof plan

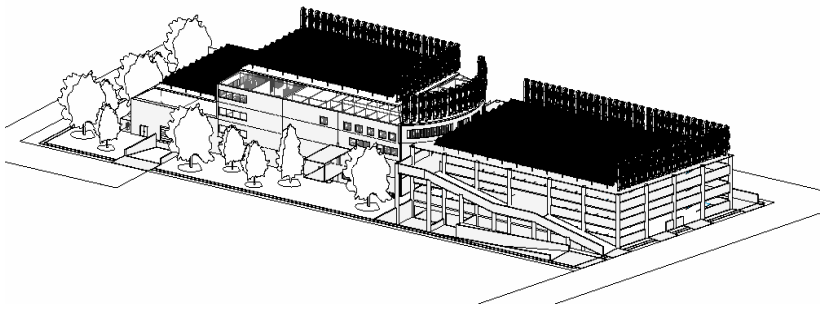

Capstone Studio 2009. Team Two, exterior perspective

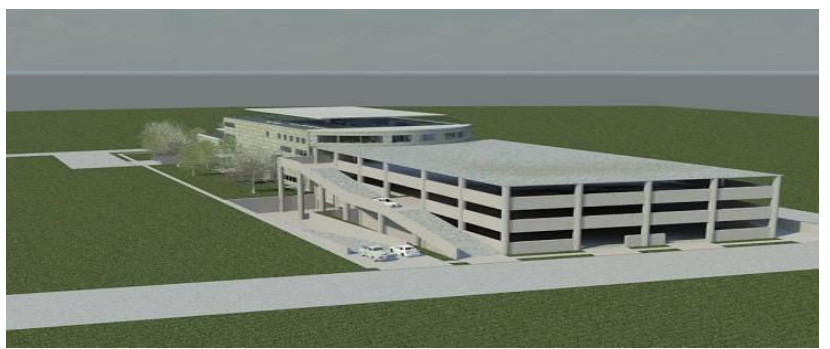

Capstone Studio 2009. Team Two, exterior rendered perspective

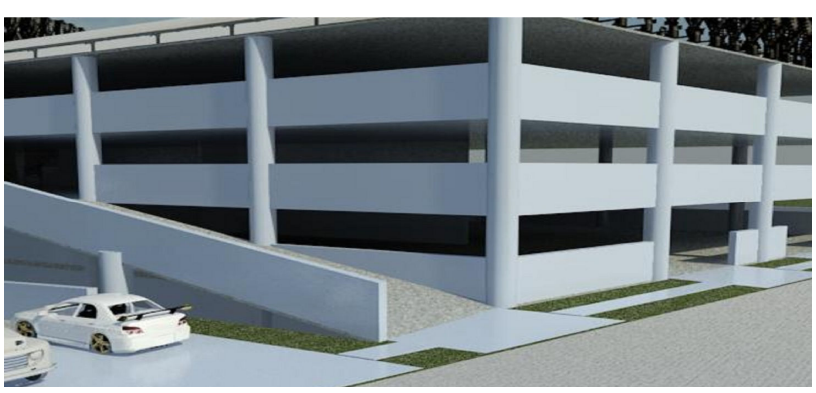

Capstone Studio 2009. Team Two, exterior rendering 


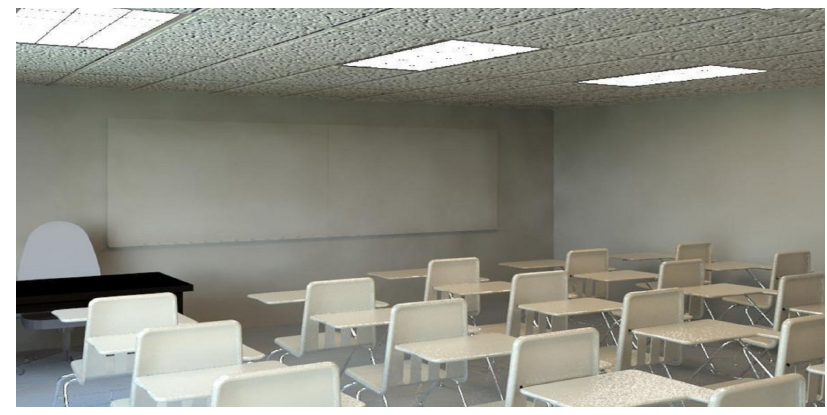

Capstone Studio 2009. Team Two, interior rendering

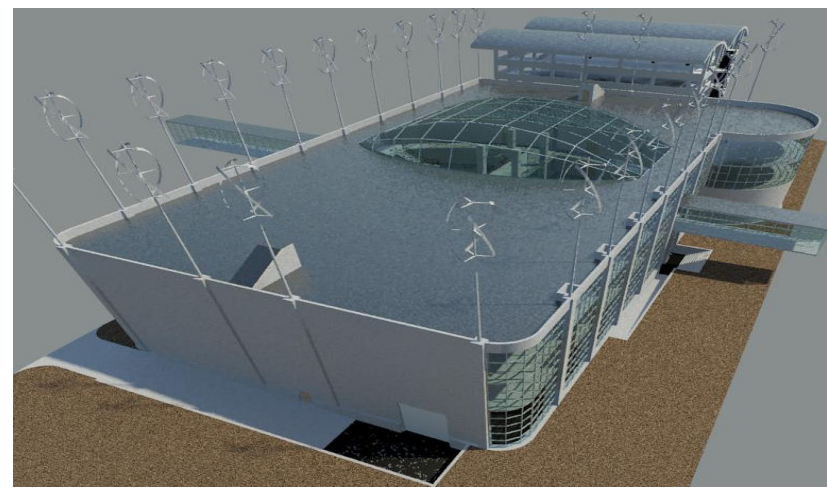

Capstone Studio 2009. Team Three, exterior rendering

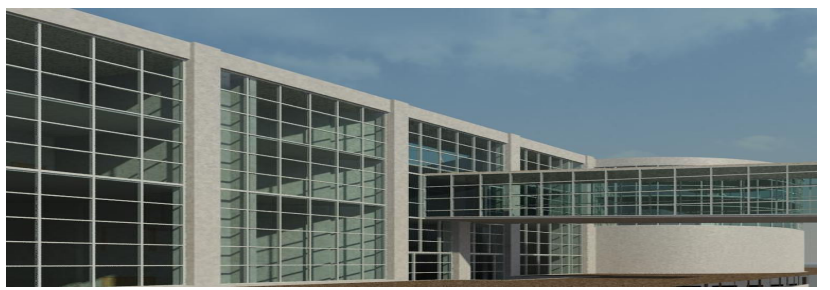

Capstone Studio 2009. Team Three, exterior rendering

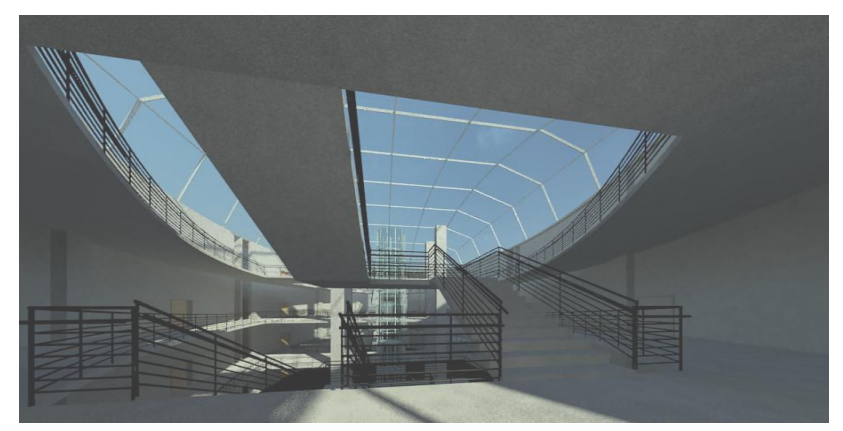

Capstone Studio 2009. Team Three, interior rendering

\section{Discussion}

A capstone project as a terminal course for a degree program is nothing new. Student collaboration, whether it be inter- or intra-disciplinary is also nothing new. What was new, unique, and challenging about the subject capstone course was the Integrated Project Design (IPD) approach coupled with the sheer size of the student body and as well as the aggressive nature of the project. The class was comprised of 47 students distributed among six different degree paths and facilitated by four instructors of differing disciplines. An additional four instructors, several advisory committee members, and the college's facility manager also contributed to the course in support roles.

The first challenge was developing a project scope with appropriate challenges for all students; this was especially true for the mechanical design students. The idea was provided via an ASHRAE webcast on Integrated Project Design; a process very different from that currently employed in industry and taught in our programs. In the end, faculty arrived at the idea of a Net Zero Energy Building (NZEB) as a design project. However, the concept of a NZEB was not discussed in significant detail in any preceding course of any program. This required we develop some methodology not only to let students come up to speed on the concept, but also allow the students to be successful in developing a design within an eleven week time frame. 
To prepare the students and the faculty to handle such an unfamiliar but timely topic in a meaningful way, we invited a subject expert to meet with us for the purpose of providing background information. The subject expert met with faculty, the program advisory committees, and conducted several sessions with students. It should be noted that the meetings with the advisory committee resulted in many of the individual advisory members taking a keen and personal interest in working with the students over the course of the capstone project. It also important to note these meetings occurred during the instructional term prior to that in which the capstone courses were conducted.

Another challenge faced by the faculty was the disparate sizes of each student discipline. For example, this graduating class only had three HVAC graduates while there were over 20 architectural technology graduates. We did consider that each discipline form a disciplinary group to act in the fashion of a consultant to provide the IPD approach we were promoting. However, we felt there was to high a probability of students reverting to the typical segregated approach most prevalent today. To prevent this, we used an integrated team approach used by many local industry consultants. We ended up with three teams, each to develop their own building. This still resulted in some teams not being staffed with certain disciplines. For example, two teams had no environmental personnel. However, since each of the three teams sited the building at the same location, the environmental personnel that were staffed on a single team provided the same information to the other teams to complete that portion of the project.

Perhaps the most difficult challenge was ensuring proper communication between students and student teams. To aid in this endeavor, we used the capabilities offered by Angel, our course delivery system, and created a community group to which was assigned all involved students, the faculty facilitators, and the faculty consultants. Within the community group, we were able to subdivide students into their respective teams. Each team had their own electronic discussion board area as provided by Angel. Within each team, the separate disciplines formed their own sub-team; all physically located within their own classroom. Between the geographic proximity and the electronic discussion boards, every team member was always apprised of what another was doing. More importantly, each discipline within the team was able to collaborate to maximize design efficiency.

What was left was to promote inter-team communications. We did so in two ways. First, we created a Team Leader team. This allowed the team leaders to communicate with each other to request information and data. We then created a faculty facilitator team to allow private communications between faculty. This was done to ensure each faculty discipline could discuss issues that arose during the course of the project.

All communication was then done only on the discussion boards. In this particular case, we encouraged students not to use email communications except for private issues not relevant to the project. The students were also required to communicate with faculty facilitators, faculty consultants, and advisory members via memo when the communication involved critical information. For example, the project statement required the building include a construction lab. The students requested details of the construction lab from the department chairperson via a formal memo. Of course, not all communication was so formal. However, where the communication between student and faculty, between student teams, or between student disciplines within the team was face-to-face, the student was required to document that communication if it was of a significant nature. 
Faculty also populated the content area of the electronic community group, referred to as the 'Library', with basic reference material. The material included items such as electronic versions of building codes, appropriate standards, and appropriate magazine articles and whitepapers. This served two purposes: 1) it simulated a consultants office environment in which such reference information would exist; 2) it allowed the students to direct their research to the problems of designing a NZEB rather than having to search out the common material and information already discussed in previous classes.

Once the project was presented to the students, we allowed the student teams to proceed in their own fashion with two basic requirements: first, develop a schedule to guide the project, and second, to conduct regular progress meetings complete with meeting minutes. The students did have the benefit of hearing industry speakers on such topics as live roofs, dedicated heat recovery chillers, variable refrigerant flow systems, etc. Although faculty invited some of these speakers, the students did take it upon themselves to research products and invite outside representatives to come in and speak to them regarding their wares. This even resulted in the offer by some representatives to help them in their design.

We did encourage innovation and out-of-the-box thinking for this project. An example of this was the mechanical student who decided to pursue the idea of using a water turbine to generate power. Next to the campus is a river and a low-head dam. After doing research into the hydraulics and the history of the flow of water through this river, he decided on a low-head water turbine. At the same time, a classmate was investigating the application of fuel cells. Eventually, the two students collaborated on the design of a low-head water turbine to generate and store hydrogen to power a hydrogen-based fuel cell. This idea captured the interest of an advisory member who works for the City of Dayton as a potential means of clean energy generation.

As one might expect, each team took a different approach to the design. One team decided to do significant research on alternative energy methods prior to establishing a building form or footprint. It was this team that discovered the concept of a solar chimney and incorporated it into their building design; despite the fact nothing of this nature was ever presented in any previous class. The other two teams tended toward the opposite approach where the building form was developed in concert with the idea of providing solar and wind energy generation. Ironically, the faculty are somewhat divided on the approach.

The reason for this division lies in the requirement for the student to provide a midterm progress report. The intent of the progress report is identical to a progress meeting in industry. The student teams were to provide the owner (represented by faculty, advisors, and campus facilities managers) with there vision of a NZEB. The team that spent time so much time on alternative energy research was not nearly as far along as the other two teams. Although most faculty considered this a problem, others did not.

During the midterm project meeting, the 'owners' made appropriate notes and commented on the students' progress, ideas, and technical viability. The students received these comments and went back to work. During the second half of the term, the students completed the project to include drawings, energy modeling, 3-D modeling, surveying reports, site construction plans and documents, and environmental reports. All of this was presented in a 'Final Project Review' meeting with all advisory members. This review took the form of a 'trade show'. Then, each team was provided a 'booth' and multimedia equipment and was allowed to present their project as they saw fit. First, each of the three design teams provided a very brief presentation and 
introduction to the advisory council. After this brief presentation, the advisory members were allowed to roam from team to team and discuss various elements of each project. Each advisor was also provided a 'grading rubric' which they used to provide feedback to the faculty facilitators.

\section{Conclusions}

A. Challenges

The three Integrated Project Design teams faced many challenges:

- Communication tools (lack of use)

- Communication attitude

- Team-building

- Completing work outside of class

- Technology (server) issues

- Technology distractions

- Late development of focus or design

\section{B. $\quad$ Strengths of Student Teams}

The Integrated Project Design teams demonstrated many strengths:

- Conducted regular team meetings

- Developed leadership over time

- Relied on some technology independent of Angel

- Passionate about their disciplines

- Proficient with technologies

\section{C. $\quad$ Suggested Improvements}

The Integrated Project Design faculty developed a list of needed improvements:

- Provide more structured schedule with additional milestones

- Require more regular team meetings

- Mandate more whole-class meetings

- Improve server access off-campus

- Enhance software functionality for team activity

- Reduce scope of building and environmental design

- Curriculum specific assessment tools

D. Successes

The Integrated Project Design faculty identified aspects of the project that work as-is:

- Kick-off event with all students

- Periodic review of work

- Attend student-lead meetings and interact

- Wrap-up event with presentation to advisory teams from various disciplines 


\section{References}

1. Boulos, Maramba and Wheeler, 2006. Maged N. Kamel Boulos, Inocencio Maramba and Steve Wheeler, Wikis, blogs and podcasts: a new generation of Web-based tools for virtual collaborative clinical practice and education. BMC Medical Education 2006, 6:41.

2. Ding, 2009. Suining Ding, An analysis of a collaborative studio: Engaging students, faculty and practitioners. Paper presented at the annual meeting of the American Society for Engineering Education, 2009.

3. Garrison and Akyol, 2009. D. Randy Garrison and Zehra Akyol, Role of instructional technology in the transformation of higher education. Journal of Computing in Higher Education, Volume 21, Number 1, Pages $19-30$.

4. Georgina and Hosford, 2009. David A. Georgina and Charles C. Hosford, Higher education faculty and perceptions on technology integration and training. Teaching and Teacher Education, Volume 25, Issue 5, July 2008, Pages 690 - 696 .

5. Georgina and Olson, 2007. David A. Georgina and Myrna R. Olson, Integration of technology in higher education: A review of faculty self-perceptions. The Internet and Higher Education, Volume 11, Issue 1, 2008, Pages $1-8$.

6. Koehler, Mishra and Yahay, 2005. Matthew J. Koehler, Punya Mishra and Kurnia Yahya, Tracing the development of teacher knowledge in a design seminar: integrating content, pedagogy and technology. Computers \& Education volume 49, Issue 3, November 2007, pages 740 - 762.

7. Nuttall, Mwangi and Baltimore, 2009. Brent Nuttall, James Mwangi and Craig Baltimore, Capstone projects: Integrating industry through student leadership. Paper presented at the annual meeting of the American Society for Engineering Education, 2009.

8. Williams and Jacobs, 2004. Jeremy B. Williams and Joanne Jacobs, Exploring the use of blogs as learning spaces in the higher education sector. Australasian Journal of Educational Technology 2004, 20(2), pages $232-247$. 